\title{
DEMETALLIZATION OF HEAVY VACUUM RESIDUUM BY TITANIUM-VANADIUM ZEOLITE ADSORBENTS
}

\author{
YERDOS ONGARBAYEV ${ }^{a, b^{*}}$, SHYNAR OTEULl ${ }^{a, b}$, \\ YERBOL TILEUBERDI ${ }^{a, b}$, GALYMZHAN MALDYBAEV $^{\mathrm{b}}$, \\ SAULE NURZHANOVA ${ }^{b}$
}

\begin{abstract}
Demetallization and desulfurization of vacuum residuum from the Pavlodar Petrochemical Plant (Kazakhstan) was carried out by adsorbents based on zeolite modified with titanium compounds and vanadium oxide. The process was carried out at a temperature of $320-360^{\circ} \mathrm{C}$ for 1 to 3 hours at atmospheric pressure. The results of determining the physico-chemical characteristics of the modified adsorbents showed that, after modification, their specific surface area increases, but the specific pore volume decreases. The maximum degree of demetallization is observed when using an adsorbent based on zeolite modified with titanium oxides and vanadium oxides. The change in the structure of vanadylporphyrins in vacuum residuum composition after the demetallization process is determined. After demetallization etioporphyrins have $\mathrm{C}_{27}-\mathrm{C}_{32}$ with a center of mass at $\mathrm{C}_{29}$, phylloporphyrins have $\mathrm{C}_{28}-\mathrm{C}_{34}$, after treatment at $360^{\circ} \mathrm{C}$, the center of mass shifts towards an increase in the number of carbon atoms $\mathrm{C}_{31}$.
\end{abstract}

Keywords: demetallization, desulfurization, heavy vacuum residuum, adsorbent, zeolite, vanadium oxide, titanium, etioporphyrins, phylloporphyrins.

\section{INTRODUCTION}

The main difficulty in using heavy oil feedstock in the petrochemical industry is the high content of asphaltenes and metal compounds, leading to accelerated deactivation of catalysts for deep oil refining. Vanadium and other metals, such as nickel and iron, are present in petroleum and its heavy residues in the form of porphyrin and asphaltene complexes. In some oils,

\footnotetext{
a Al-Farabi Kazakh National University, Faculty of Chemistry and Chemical Technology, AlFarabi Pr., 71, 050040, Almaty, Kazakhstan

b Institute of Combustion Problems, Bogenbai batyr Str., 172, Almaty, Kazakhstan

* Corresponding author: Erdos.Ongarbaev@kaznu.kz
} 
the vanadium content can reach $1200 \mathrm{ppm}$ and the porphyrin vanadium content can vary from 20 to $50 \%$ of the total vanadium. Vanadium present in the combustion products of liquid fuels catalyzes the oxidation of sulfur dioxide to sulfur trioxide, leading to corrosion and the formation of acid rain.

For the preparation of heavy oil feedstock for deep processing at refineries, preliminary deasphalting and demetallization processes are used, in which the viscosity, density and coking behavior of oil products decrease, the content of metal compounds in it decreases and clarification occurs. The removal of asphaltenes also results in the removal of complexes of vanadium, nickel and organic compounds with heteroatoms, especially nitrogen and sulfur.

Currently, in the oil industry, the demetallization of heavy oil feedstock is carried out by the processes of solvent extraction, deasphalting, hydrogenation and thermal destruction.

The methods of solvent extraction are quite expensive and complex, require very large quantities of solvent in relation to the feedstock, their efficiency and yield are not completely satisfactory, they give large quantities of asphaltene streams and are not suitable for separating metals, such as porphyrin vanadium and nickel, which are not completely removed with asphaltene fraction. One of the main drawbacks of the process is the high energy consumption for solvent regeneration, associated with the need to evaporate it from the asphalt-free oil solution, as well as condensation and compression after its residues are separated in the stripping columns [1]. It is also worth noting the small outputs of the vacuum residue, while maintaining an acceptable composition and properties, in particular the content of metals, heteroatoms and coke residue.

In recent years, catalytic methods have been considered as effective methods for deasphalting and demetallization.

Solid-acid catalysts for hydrocracking high-boiling mineral oils [2] in the presence of hydrogen using polyvalent metal phosphates - $40-80 \%$ $\mathrm{AlPO}_{4}, 35 \% \mathrm{FePO}_{4}$ in the xerogel form with $5-10 \%$ sodium fluoride have been proposed. The disadvantage of this method is not only the impossibility of using viscous vacuum residues on stationary catalysts as raw materials, but also deactivation of the catalyst by hetero-organic compounds, and thermal instability of the used catalyst during regeneration after the formation of coke on the surface.

Thermal adsorption (or thermo-contact-adsorption) processing is among the effective processes of deasphalting and demetallization. In the processes of thermo-adsorption refining there is no hardly-utilizable asphaltite formed during solvent deasphalting. In refining, four main processes of thermoadsorption refining of hydrocarbon residues are used: ART (Asphalt Residual Treating) and 3D (discriminatory destructive distillation), developed in the USA, and ACC (adsorption-contact cleaning) and ETCC (express thermal- 
contact cracking), created in Russia. The processes of ART and ACO are processes with lift-reactor type adsorbers, and the processes of $3 \mathrm{D}$ and ETCC are processes with adsorbing reactors that have an ultrashort contact time of the raw material with the adsorbent.

In the process of thermal contact cracking of heavy oil residues, granular or powdered solid materials are used, the so-called contact adsorbents, on the particles of which physical and chemical processes take place and the transformation of raw materials with the formation of coke and the adsorption of metals from the cracked raw material.

One of the first processes of this variety, mastered in industry, is the ART process, which is a combination of processes of partial evaporation of raw materials and its decarbonization and demetallization in the fluidized bed of the adsorbent. The process pressure is $0.1-0.2 \mathrm{MPa}$, the temperature is $450-550{ }^{\circ} \mathrm{C}$. As an adsorbent with the trade name Artkat [3], a microspherical inert adsorbent based on kaolin with a low specific surface (about $15 \mathrm{~m}^{2} / \mathrm{g}$ ) is used, which has a good affinity for asphaltenes and metals. However, if oil residues are used in contact cracking processes, it is destroyed due to the deposition of a larger amount of coke and a high burning-out temperature of the latter. In addition, it has a high cost, since it is manufactured in special factories.

The following contact adsorbents for thermal cracking of petroleum residues are known: powdered petroleum coke [4], oxide contact — iron ore pellets [5]. The disadvantages of petroleum coke are low strength and very low porosity, so it quickly collapses and poorly adsorbs metals from raw materials. Pellets of iron ore have a high density and strength, but practically do not possess porosity. When they are used, energy consumption increases for the circulation of the contact adsorbent between the reaction apparatus and for maintaining its fluidized bed. Pellets poorly adsorb metals from raw materials and the resulting coke.

Adsorption-catalytic materials containing rare and rare-earth metals are increasingly used in refining processes. Vanadium-titanium systems are widely used as catalysts for such industrial processes as the partial oxidation of hydrocarbons and the removal of nitrogen oxides from gas mixtures. Therefore, many studies have been devoted to studying the properties of $\mathrm{V}_{2} \mathrm{O}_{5} / \mathrm{TiO}_{2}$ systems using a wide variety of research methods [6].

In recent years, researchers have paid special attention to intercalation compounds based on xerogel vanadium ( $\mathrm{V}$ ) oxide, exhibiting the properties of both the original vanadium-oxygen matrix and the implanted substances. A characteristic feature of such compounds is the quasi-one-dimensional structure of the layers and their turbostratic disordering. Not only cations, but also molecules of organic compounds can be easily incorporated into this structure. 
YERDOS ONGARBAYEV, SHYNAR OTEULI, YERBOL TILEUBERDI,

GALYMZHAN MALDYBAEV, SAULE NURZHANOVA

In a previous work [7], we carried out demetallization and desulfurization of vacuum residuum from the Pavlodar petrochemical plant with an adsorbent based on zeolite modified with xerogel vanadium $(\mathrm{V})$ oxide.

In this work, demetallization of vacuum residuum was carried out with a zeolite adsorbent modified with vanadium and titanium oxides at various temperatures and durations of the process.

\section{RESULTS AND DISCUSSION}

To carry out the process of demetallization and desulfurization of vacuum residuum from the Pavlodar Petrochemical Plant, samples of zeolite modified with titanium (IV) compounds and vanadium oxide (V) were prepared as adsorbents.

Table 1 presents the main physico-chemical characteristics of adsorbents based on zeolite modified with titanium compounds and xerogel vanadium (V) oxide obtained by the sol-gel method.

The main carrier of adsorbents is zeolite $\mathrm{KN}-4$ of the Novosibirsk Chemical Concentrates Plant, which has the following characteristics: specific surface area $329 \mathrm{~m}^{2} / \mathrm{g}$, mechanical strength $5.9 \mathrm{MPa}$, granule diameter 3.1$4.0 \mathrm{~mm}, \mathrm{Al}_{2} \mathrm{O}_{3}$ mass fraction $-10.13 \%$. To improve the adsorption characteristics, the zeolite is modified with vanadium oxide $(\mathrm{V})$ and titanium compounds. As can be seen from table 1 , when modifying a zeolite with vanadium oxide $(\mathrm{V})$ xerogel, the specific surface area increases from 329 to $376.5 \mathrm{~m}^{2} / \mathrm{g}$, but the specific pore volume decreases from 0.173 to $0.161 \mathrm{~cm}^{3} / \mathrm{g}$, the average pore size increased slightly. Modifying the zeolite with titanium oxysulfate in an amount of $1 \%$ also increases the specific surface of the carrier from 329 to $336.6 \mathrm{~m}^{2} / \mathrm{g}$, while the specific pore volume also decreases, the average pore size remains unchanged. Zeolite modified with $1 \% \mathrm{TiCl}_{4}$ and $1 \% \mathrm{~V}_{2} \mathrm{O}_{5}$ showed lower values of specific surface and specific pore volume in comparison with indicators of initial zeolite.

Table 1. Physico-chemical characteristics of adsorbents

\begin{tabular}{|l|c|c|c|}
\hline \multicolumn{1}{|c|}{ Adsorbents } & $\begin{array}{c}\text { Specific surface, } \\
\mathrm{m}^{2} / \mathrm{g}\end{array}$ & $\begin{array}{c}\text { Specific pore } \\
\text { volume, } \mathrm{cm}^{3} / \mathrm{g}\end{array}$ & $\begin{array}{c}\text { Average pore } \\
\text { size, } \mathrm{nm}\end{array}$ \\
\hline Zeolite $\mathrm{KN}-4$ & 329,0 & 0,173 & 1,713 \\
\hline $\begin{array}{l}\text { Zeolite modified with } \\
1 \% \mathrm{~V}_{2} \mathrm{O}_{5} \text { xerogel }\end{array}$ & 376,5 & 0,161 & 1,714 \\
\hline $\begin{array}{l}\mathrm{Zeolite} \text { modified with } \\
1 \% \mathrm{TiOSO}\end{array}$ and $1 \% \mathrm{~V}_{2} \mathrm{O}_{5}$ & 336,6 & 0,144 & 1,713 \\
\hline $\begin{array}{l}\mathrm{Zeolite} \text { modified with } \\
1 \% \mathrm{TiCl}_{4} \text { and } 1 \% \mathrm{~V}_{2} \mathrm{O}_{5}\end{array}$ & 312,6 & 0,134 & 1,714 \\
\hline
\end{tabular}


The data of Table 2 presents the results of determining the content of sulfur and metals in the vacuum residuum composition after demetallization at temperatures from 320 to $360{ }^{\circ} \mathrm{C}$ with an adsorbent - zeolite modified with $1 \%$ titanium oxysulfate and $1 \%$ vanadium oxide. As can be seen from the tabular data, the sulfur content in the vacuum residuum decreases at $340{ }^{\circ} \mathrm{C}$ from 1.72 to $1.28 \%$, which gives a degree of desulfurization of $25.6 \%$. The metal content at all temperatures decreases slightly - vanadium from 0.054 to $0.017 \%$, nickel from 0.0058 to $0.0022 \%$, iron from 0.0033 to $0.0027 \%$.

Table 3 shows the results of determining the elemental composition of vacuum residuum after demetallization with an adsorbent, a zeolite modified with $1 \%$ titanium chloride and $1 \%$ vanadium oxide at temperatures of 320 and $360{ }^{\circ} \mathrm{C}$. As can be seen from the table, the content of nitrogen, carbon and hydrogen decreases after demetallization. A decrease of the sulfur content is observed at a temperature of $360{ }^{\circ} \mathrm{C}$ after demetallization within 2 hours. The content of sulfur is reduced from 1.72 to $0.98 \%$.

Table 2. The content of metals and sulfur in the composition of vacuum residuum after demetallization with zeolite modified with $1 \% \mathrm{TiOSO}_{4}$ and $1 \% \mathrm{~V}_{2} \mathrm{O}_{5}$

\begin{tabular}{|l|c|c|c|c|}
\hline \multicolumn{1}{|c|}{ Sample } & $\mathrm{S}, \%$ & $\mathrm{~V}, \%$ & $\mathrm{Ni}, \%$ & $\mathrm{Fe}, \%$ \\
\hline Vacuum residuum & 1,72 & 0,054 & 0,0058 & 0,0033 \\
\hline $\begin{array}{l}\text { Vacuum residuum after demetallization } \\
\text { at } 320^{\circ} \mathrm{C}\end{array}$ & 1,46 & 0,020 & 0,0023 & 0,0030 \\
\hline $\begin{array}{l}\text { Vacuum residuum after demetallization } \\
\text { at } 340^{\circ} \mathrm{C}\end{array}$ & 1,28 & 0,017 & 0,0022 & 0,0027 \\
\hline $\begin{array}{l}\text { Vacuum residuum after demetallization } \\
\text { at } 360^{\circ} \mathrm{C}\end{array}$ & 1,49 & 0,017 & 0,0023 & 0,0031 \\
\hline
\end{tabular}

Table 3. Results of the analysis of the elemental composition of the samples

\begin{tabular}{|c|c|c|c|c|}
\hline Sample & $\mathrm{N}, \%$ & C, \% & $\mathrm{H}, \%$ & S, \% \\
\hline Vacuum residuum & 0,51 & 87,04 & 11,512 & 1,720 \\
\hline $\begin{array}{l}\text { Vacuum residuum after demetallization } \\
\text { at } 320^{\circ} \mathrm{C}\end{array}$ & 0,47 & 86,35 & 11,387 & 1,213 \\
\hline $\begin{array}{l}\text { Vacuum residuum after demetallization } \\
\left.\text { at } 360^{\circ} \mathrm{C} \text { ( } 1 \text { hour }\right)\end{array}$ & 0,43 & 86,67 & 11,433 & 1,373 \\
\hline $\begin{array}{l}\text { Vacuum residuum after demetallization } \\
\text { at } 360^{\circ} \mathrm{C} \text { ( } 2 \text { hour) }\end{array}$ & 0,48 & 89,96 & 11,113 & 0,987 \\
\hline $\begin{array}{l}\text { Zeolite modified with } 1 \% \mathrm{TiCl}_{4} \text { and } \\
1 \% \mathrm{~V}_{2} \mathrm{O}_{5}\end{array}$ & -1. & 0,46 & 0,346 & - \\
\hline $\begin{array}{l}\text { Zeolite modified with } 1 \% \mathrm{TiCl}_{4} \text { and } \\
1 \% \mathrm{~V}_{2} \mathrm{O}_{5} \text { after demetallization }\end{array}$ & 0,06 & 18,95 & 2,555 & 0,008 \\
\hline
\end{tabular}


Table 3 also shows the compositions of the adsorbent before and after demetallization. After treatment, the content of the adsorbent increases the carbon content by $18.5 \%$, hydrogen by $2.2 \%$ and sulfur by $0.008 \%$, which confirms its desulfurizing adsorption capacity.

Table 4 presents the changes in the content of metals in the composition of vacuum residuum after treatment with zeolite modified with $2 \% \mathrm{~V}_{2} \mathrm{O}_{5}$ and $10 \% \mathrm{TiO}_{2}$ at different temperatures. As can be seen from the tabular data, the maximum decrease in the metal content is observed in the vacuum residuum composition after treatment at $340{ }^{\circ} \mathrm{C}$. The degree of extraction of vanadium was $35.5 \%$, nickel $40.5 \%$, iron $37.3 \%$, copper $56.3 \%$, manganese $46.9 \%$.

The adsorption capacity of the tested adsorbents is due to the fact that the layered structure of the xerogel vanadium $(\mathrm{V})$ oxide is retained when vanadium is replaced by four- and hexavalent ions. It has been established that even small additions of titanium contribute to the polymerization of sols and the production of stable gels. Intercalation compounds based on such complex vanadium and titanium oxides are characterized by high intercalation capacity and thermal stability.

Table 4. Metal content in the composition of vacuum residuum before and after demetallization with zeolite modified with $2 \% \mathrm{~V}_{2} \mathrm{O}_{5}$ and $10 \% \mathrm{TiO}_{2}$

\begin{tabular}{|l|c|c|c|c|c|}
\hline \multicolumn{1}{|c|}{ Sample } & $\mathrm{V}, \mathrm{mg} / \mathrm{kg}$ & $\mathrm{Ni}, \mathrm{mg} / \mathrm{kg}$ & $\mathrm{Fe}, \mathrm{mg} / \mathrm{kg}$ & $\mathrm{Cu}, \mathrm{mg} / \mathrm{kg}$ & $\mathrm{Mn}, \mathrm{mg} / \mathrm{kg}$ \\
\hline Vacuum residuum & 178,7 & 67,00 & 20,63 & 4,856 & 0,2669 \\
\hline $\begin{array}{l}\text { Vacuum residuum } \\
\text { after treatment at } \\
320^{\circ} \mathrm{C}\end{array}$ & 134,9 & 46,65 & 19,81 & 4,01 & 0,2269 \\
\hline $\begin{array}{l}\text { Vacuum residuum } \\
\text { after treatment at } \\
340^{\circ} \mathrm{C}\end{array}$ & 115,2 & 39,83 & 12,94 & 2,122 & 0,1416 \\
\hline $\begin{array}{l}\text { Vacuum residuum } \\
\text { after treatment at } \\
360^{\circ} \mathrm{C}\end{array}$ & 134,4 & 46,94 & 17,15 & 3,49 & 0,2229 \\
\hline
\end{tabular}

According to the results of SARA analysis (Table 5), the main components of the original vacuum residuum are aromatic hydrocarbons $(45.7 \%)$, resins $(20.5 \%)$ and asphaltenes (27.2\%). After demetallization, a decrease in the asphaltene content by $7.5 \%$, a slight change in the vacuum residuum content and an increase in the content of saturated and aromatic hydrocarbons are observed. The resin-asphaltene part of vacuum residuum is adsorbed on the sorbent with partial thermal destruction. The maximum change in the content of components is also observed during demetallization by a sorbent at a temperature of $340^{\circ} \mathrm{C}$. 
Table 5. Group composition of vacuum residuum before and after demetallization with zeolite modified with $2 \% \mathrm{~V}_{2} \mathrm{O}_{5}$ and $10 \% \mathrm{TiO}_{2}$

\begin{tabular}{|l|c|c|c|c|}
\hline \multicolumn{1}{|c|}{ Sample } & $\begin{array}{c}\text { Saturated } \\
\text { hydrocarbons, } \\
\%\end{array}$ & $\begin{array}{c}\text { Aromatic } \\
\text { hydrocarbons, } \\
\%\end{array}$ & $\begin{array}{c}\text { Resins, } \\
\%\end{array}$ & $\begin{array}{c}\text { Asphalte- } \\
\text { nes, } \%\end{array}$ \\
\hline Vacuum residuum & 6,6 & 45,7 & 20,5 & 27,2 \\
\hline $\begin{array}{l}\text { Vacuum residuum after } \\
\text { treatment at } 320^{\circ} \mathrm{C}\end{array}$ & 7,2 & 47,4 & 19,9 & 25,5 \\
\hline $\begin{array}{l}\text { Vacuum residuum after } \\
\text { treatment at } 340^{\circ} \mathrm{C}\end{array}$ & 9,1 & 51,7 & 19,5 & 19,7 \\
\hline $\begin{array}{l}\text { Vacuum residuum after } \\
\text { treatment at } 360^{\circ} \mathrm{C}\end{array}$ & 8,8 & 50,4 & 20,4 & 20,4 \\
\hline
\end{tabular}

Table 6. Elemental composition (\%) of adsorbents

\begin{tabular}{|c|c|c|c|c|}
\hline Element & Zeolite & $\begin{array}{l}\text { Zeolite with } \\
\text { c } 1 \% \mathrm{~V}_{2} \mathrm{O}_{5}\end{array}$ & \begin{tabular}{|c|} 
Zeolite with $2 \%$ \\
$\mathrm{~V}_{2} \mathrm{O}_{5}$ and $10 \% \mathrm{TiO}_{2}$
\end{tabular} & $\begin{array}{c}\text { Zeolite with } 2 \% \mathrm{~V}_{2} \mathrm{O}_{5} \text { and } \\
10 \% \mathrm{TiO}_{2} \text { after process }\end{array}$ \\
\hline $\mathrm{O}$ & 52,289 & 51,983 & 51,314 & 52,375 \\
\hline $\mathrm{Si}$ & 40,514 & 39,229 & 37,485 & 39,857 \\
\hline $\mathrm{Al}$ & 6,667 & 7,29 & 5,938 & 6,407 \\
\hline $\mathrm{Zr}$ & 0,305 & 0,580 & 0,438 & 0,406 \\
\hline $\mathrm{Fe}$ & 0,092 & 0,119 & 0,076 & 0,101 \\
\hline $\mathrm{Na}$ & 0,032 & 0,034 & 0,437 & 0,048 \\
\hline $\mathrm{Nb}$ & 0,025 & 0,081 & 0,035 & 0,034 \\
\hline $\mathrm{Mg}$ & 0,020 & 0,028 & - & 0,023 \\
\hline $\mathrm{Hf}$ & 0,020 & 0,030 & 0,024 & 0,022 \\
\hline $\mathrm{Cl}$ & 0,017 & 0,030 & - & 0,027 \\
\hline$S$ & 0,007 & 0,045 & 0,003 & 0,685 \\
\hline $\mathrm{Cr}$ & 0,006 & - & - & - \\
\hline $\mathrm{Ni}$ & 0,006 & 0,010 & 0,005 & 0,003 \\
\hline $\mathrm{Cu}$ & - & 0,005 & 0,003 & 0,0033 \\
\hline $\mathrm{Ir}$ & - & 0,003 & 0,003 & 0,003 \\
\hline $\mathrm{Sr}$ & - & 0,003 & 0,002 & - \\
\hline $\mathrm{Zn}$ & - & 0,002 & 0,002 & 0,002 \\
\hline $\mathrm{Bi}$ & - & 0,001 & - & - \\
\hline As & - & 0,001 & 0,001 & - \\
\hline $\mathrm{Pb}$ & - & 0,000 & 0,000 & - \\
\hline $\mathrm{V}$ & - & 0,595 & 1,915 & - \\
\hline $\mathrm{Ti}$ & - & - & 2,108 & 0,002 \\
\hline
\end{tabular}

The elemental composition of the prepared adsorbents before and after the tests is presented in Table 6 . The content of the initial zeolite is dominated by the content of oxygen, silicon, aluminum. When modifying with 
$1 \%$ vanadium $(\mathrm{V})$ oxide, the content of oxygen and silicon slightly decreases, the content of vanadium is $0.595 \%$. With further modification of $10 \%$ titanium oxide, the content of oxygen, silicon and aluminum also decreases, the content of vanadium is $1.915 \%$, and titanium - 2.108. The elemental composition of the adsorbent after demetallization showed an increase in the iron content by $32.3 \%$, sulfur - from 0.003 to $0.685 \%$. However, there is a decrease in the content of nickel, vanadium and titanium.

Figure 1 shows the positive-ion ESI FT-ICR MS broadband spectra of the initial vacuum residue sample and after demetallization at 320, 340 and $360{ }^{\circ} \mathrm{C}$ with zeolite modified with $2 \% \mathrm{~V}_{2} \mathrm{O}_{5}$ and $10 \% \mathrm{TiO}_{2}$. As can be seen from the figure, the spectrum of the vacuum residuum differs from its spectra after demetallization. In the spectra before and after demetallization, peaks with maximum intensity are observed at various values of $\mathrm{m} / \mathrm{z}$.
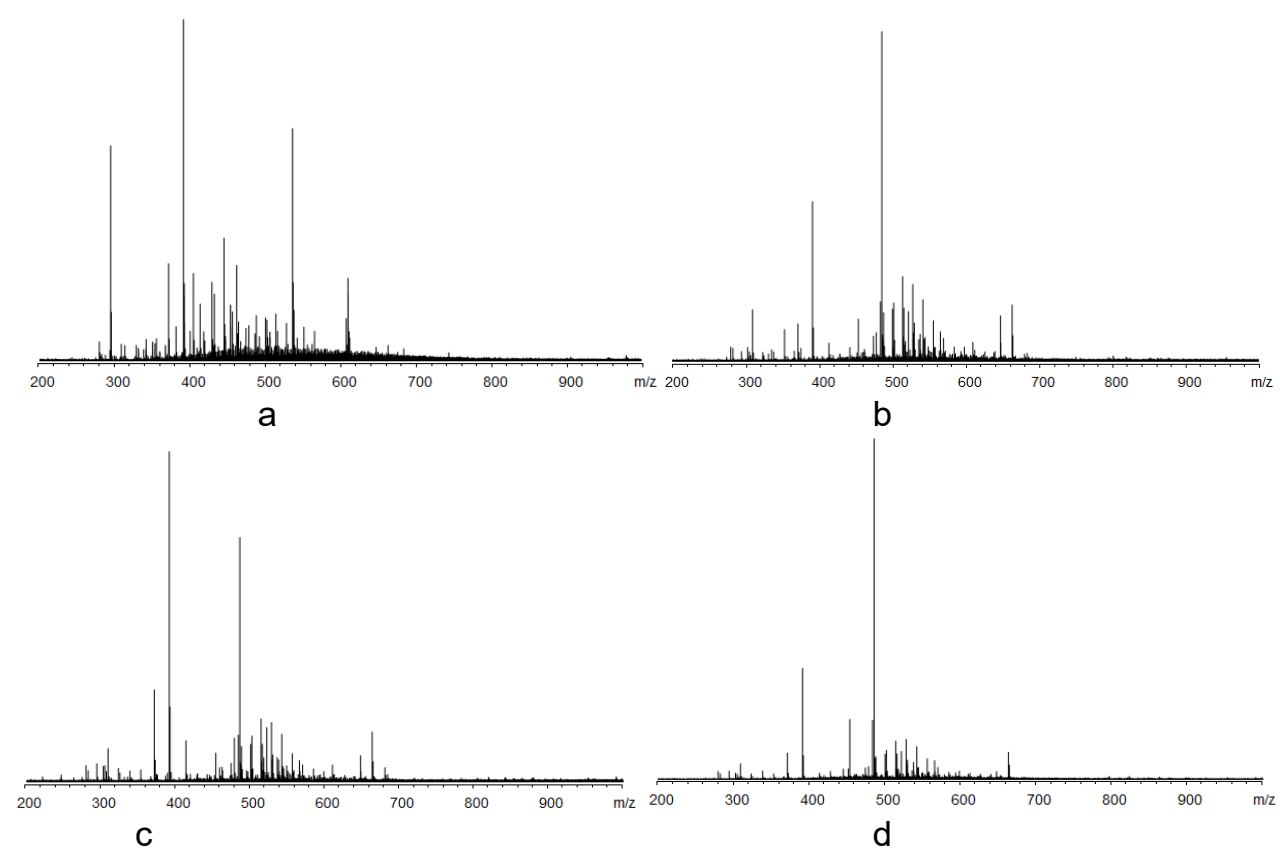

Figure 1. ESI FT-ICR MS broadband spectra of initial vacuum residuum (a) and after demetallization at $320^{\circ} \mathrm{C}(\mathrm{b}), 340^{\circ} \mathrm{C}$ (c) and $360^{\circ} \mathrm{C}$ (d)

Figure 2 shows the iso-abundance plots of DBE as a function of the carbon number for vanadyl porphyrins in the samples, derived from positiveion ESI FT-ICR mass spectra. The double-bond equivalence (DBE) is defined as the number of double bonds plus rings. The double bond in the vanadyl 
group $(\mathrm{V}=\mathrm{O})$ is not counted in DBE for which only co-valent double bonds connected with carbon atoms are considered. Only, alkyl porphyrins containing the main structure $\mathrm{N}_{4} \mathrm{VO}$ have been discovered. The etio porphyrins (ETIO) $\left(\mathrm{C}_{\mathrm{n}} \mathrm{H}_{2 \mathrm{n}-28} \mathrm{~N}_{4} \mathrm{~V}_{1} \mathrm{O}_{1}\right.$, corresponding to $\left.\mathrm{DBE}=17\right)$ and deoxophylloerythroetio porphyrins (DPEP) $\left(\mathrm{C}_{n} \mathrm{H}_{2 n-30} \mathrm{~N}_{4} \mathrm{~V}_{1} \mathrm{O}_{1}\right.$, corresponding to $\left.\mathrm{DBE}=18\right)$ were the most abundant vanadium porphyrin detected in these samples. The carbon numbers of ETIO were $\mathrm{C}_{27}-\mathrm{C}_{33}$, with a center of mass at $\mathrm{C}_{29}$. The DPEPs had $\mathrm{C}_{28}-\mathrm{C}_{34}$, with a center of mass at $\mathrm{C}_{31}$.

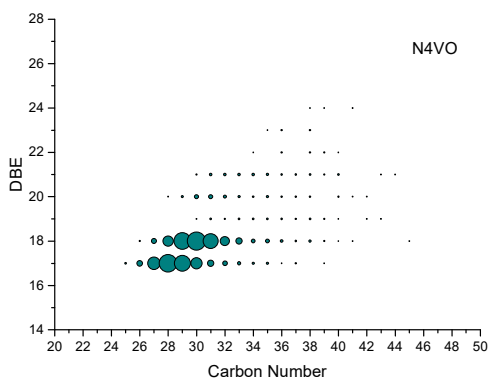

a

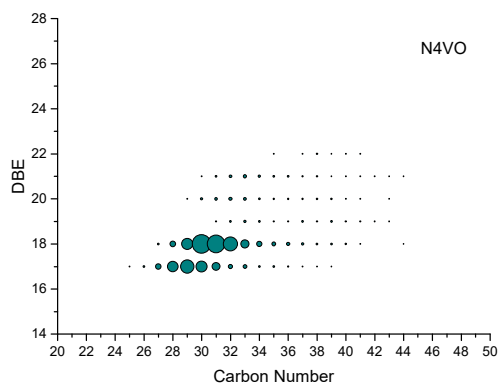

C

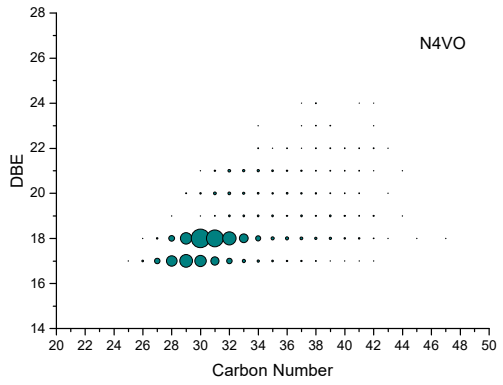

b

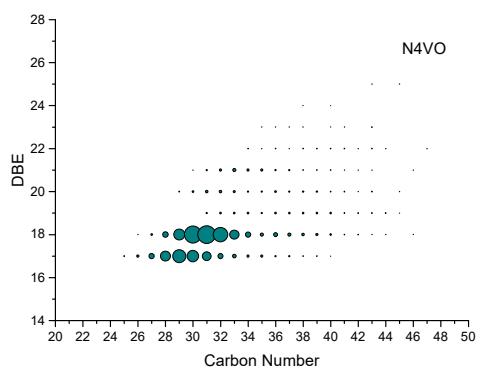

d

Figure 2. Iso-abundant plots of DBE as a function of the carbon number for each type of vanadyl porphyrins derived from positive-ion ESI FT-ICR mass spectra of initial vacuum residuum (a) and after demetallization at $320^{\circ} \mathrm{C} \mathrm{(b),} 340^{\circ} \mathrm{C}$ (c) and $360^{\circ} \mathrm{C}(\mathrm{d})$

In the composition of the initial vacuum residuum, etioporphyrins have $\mathrm{C}_{26}-\mathrm{C}_{32}$ with a center of mass at $\mathrm{C}_{28}$, which corresponds to the composition of $\mathrm{C}_{28} \mathrm{H}_{29} \mathrm{~N}_{4}$ VO. Phylloporphyrins have $\mathrm{C}_{27}-\mathrm{C}_{33}$ with a maximum content at $\mathrm{C}_{30}$, this corresponds to the formula $\mathrm{C}_{30} \mathrm{H}_{31} \mathrm{~N}_{4} \mathrm{VO}$. 
As can be seen from Figure 2, the samples of vacuum residuum after demetallization show the same pattern of petroporphyrins. After processing of vacuum residuum, the content of etioporphyrins decreases and their center of mass shifts. After demetallization at three different temperatures, etioporphyrins have $\mathrm{C}_{27}-\mathrm{C}_{32}$ with a center of mass at $\mathrm{C}_{29}\left(\mathrm{C}_{29} \mathrm{H}_{31} \mathrm{~N}_{4} \mathrm{VO}\right)$. The size of the point has decreased compared with the data for the initial vacuum residuum.

In samples of vacuum residuum after demetallization at three temperatures, phylloporphyrins have $\mathrm{C}_{28}-\mathrm{C}_{34}$, however, their maximum content remains unchanged at $\mathrm{C}_{30}$ after demetallization of 320 and $340{ }^{\circ} \mathrm{C}$. While after treatment at $360{ }^{\circ} \mathrm{C}$, the center of mass shifts towards an increase in the number of carbon atoms $\mathrm{C}_{31}$, which corresponds to the composition of $\mathrm{C}_{31} \mathrm{H}_{33} \mathrm{~N}_{4} \vee \mathrm{V}$.

\section{EXPERIMENTAL SECTION}

As a heavy oil residue used vacuum residuum of the Pavlodar Petrochemical Plant (Kazakhstan). The main carrier of sorbents is the zeolite of the Novosibirsk Chemical Concentrates Plant (Russia), which has the following characteristics: specific surface area $329 \mathrm{~m}^{2} / \mathrm{g}$, mechanical strength 5.9 MPa, granule diameter 3.1-4.0 mm, mass fraction of $\mathrm{Al}_{2} \mathrm{O}_{3}-10.13 \%$. For the preparation of the sorbent, the zeolite is modified with vanadium $(\mathrm{V})$ oxide in the amount of $2 \%$ and titanium (IV) oxide in the amount of $10 \%$.

The process of demetallization of vacuum residuum was carried out in a steel two-section reactor at temperatures of $320-360^{\circ} \mathrm{C}$ and atmospheric pressure. The duration of the experiment was 3 hours, the consumption of raw materials was $1 \mathrm{l} / \mathrm{h}$.

Metals contents in the samples were detected using an atomic absorption spectrometer.

For SARA analysis the asphaltenes were collected from the samples of vacuum residuum by precipitation in petroleum ether (a boiling range of $30-60{ }^{\circ} \mathrm{C}$ ), followed by titration. The extracted-asphaltenes fractions were then separated into saturates, aromatics and resins by column chromatography (silica gel:alumina $=4: 1$ ), using hexane, benzene and methanol as eluents, respectively.

Fouier transform ion cyclotron resonance mass spectrometry (FT-ICR MS) has been used to quantify the composition of highly complex hydrocarbon mixtures. FT-ICR resolving power has the highest available broadband mass resolution, mass resolving power, and mass accuracy, which enables the assignment of a unique elemental composition to each peak in the mass spectrum [8-10]. 
For FT-ICR MS analysis $10 \mathrm{mg}$ of asphaltenes was mixed with $1 \mathrm{ml}$ of toluene. A $20 \mu \mathrm{l}$ of the toluene solution was diluted with $1 \mathrm{ml}$ of $1: 3$ toluene:methanol. The toluene and methanol used were analytical reagent grade that were distilled twice and kept in glass bottles with ground glass stoppers. Glassware was used for solvent handling and transfer, except the stell pistons for $10 \mu \mathrm{l}$ Hamilton syringes.

The asphaltene sample was analyzed using a Bruker Apex-Ultra FTICR MS equipped with a 9.4 T superconducting magnet. The sample solution was infused into an Apollo II electrospray ionization source at $180 \mu \mathrm{l} / \mathrm{h}$ using a syringe pump. $\mathrm{HCOONH}_{4}$ was added into the solution as ionization promoter to enhance the response of low-polar compounds in positive-ion ESI.

The conditions for positive ion operation were $-4.5 \mathrm{kV}$ spray shield voltage, $-5.0 \mathrm{kV}$ capillary column front and voltage, and $310 \mathrm{~V}$ capillary column end voltage. Ions accumulated for $0.001 \mathrm{~s}$ in a hexapole with $2.0 \mathrm{~V}$ DC voltage and $500 \mathrm{Vpp}$ RF amplitude. Optimized mass for Q1 was $300 \mathrm{Da}$. Hexapoles of the Qh-Interface were operated at $5 \mathrm{MHz}$ and $800 \mathrm{Vp}-\mathrm{p}$ RF amplitude, in which ions accumulated for $1.2 \mathrm{~s}$. The delay was set to $1.3 \mathrm{~ms}$ to transfer the ions to an ICR cell by electrostatic focusing of transfer optics. ICR was operated at 13.84 dB attenuation, 193-1000 Da mass range. The FT-ICR data were acquired in $4 \mathrm{M}$ with a transient time about $2.936 \mathrm{~s}$, resulting in a resolving power of roughly 450,000 at $\mathrm{m} / \mathrm{z} 500$. Time domain data sets were coadded from 128 acquisitions.

The mass spectral peaks were mass calibrated using a Agilent "Tuning Mix" standard acetonitrile solution with 7 peaks covering a mass range from 118 to $1500 \mathrm{Da}$. In general, $1 \mathrm{ppm}$ mass accuracy can be achieved with external calibration. Bruker DA molecular formula tool assisted in identifying a major homologous series. Internal calibration was then performed using the identified vanadyl porphyrins series. On average, $\sim 0.4 \mathrm{ppm}$ mass accuracy can be achieved with internal mass calibration. Peaks with relative abundance greater than 5 times the standard deviation of the baseline noise were collected and analyzed using the in-house software. Species with different values of DBE and carbon number along with their isotopes were searched within a tolerance of \pm 0.001 Kendrick mass defect (KMD) to group into different heteroatom classes.

\section{CONCLUSION}

Thus, the results of studies and analyzes have shown the possibility of extracting metals from heavy petroleum residues by thermo-adsorption treatment with adsorbents based on zeolite modified with vanadium oxide and titanium compounds. 
The physico-chemical characteristics of the modified adsorbents based on zeolite were determined. Modifying the zeolite with vanadium oxide (V) xerogel increases the specific surface from 329 to $376.5 \mathrm{~m}^{2} / \mathrm{g}$, while the specific pore volume decreases from 0.173 to $0.161 \mathrm{~cm}^{3} / \mathrm{g}$. Modifying the zeolite with titanium oxysulfate in an amount of $1 \%$ increases the specific surface of the carrier from 329 to $336.6 \mathrm{~m}^{2} / \mathrm{g}$, the average pore size remains unchanged. Zeolite modified with $1 \% \mathrm{TiCl}_{4}$ and $1 \% \mathrm{~V}_{2} \mathrm{O}_{5}$ showed lower values of specific surface, specific pore volume in comparison with indicators of initial zeolite.

The content of elements in the composition of adsorbents before and after demetallization and desulfurization was determined. Vanadiumcontaining compounds have been identified before and after vacuum residuum demetallization. A change in the amount of vanadylporphyrins after the demetallization process has been detected.

The results of the process of demetallization of vacuum residuum on modified adsorbents showed the possibility of extraction of metals and sulfur and the correlation of the values of the specific surface of the adsorbents and the degree of extraction of metals. The maximum degree of iron extraction is provided by the zeolite modified with $1 \%$ titanium oxysulfate and $1 \%$ vanadium oxide, which has a high specific surface compared with other adsorbents, modified with titanium compounds. The adsorption capacity of the tested adsorbents is due to the fact that the layered structure of the xerogel vanadium oxide (V) is retained when vanadium is replaced by four- and hexavalent ions. It has been established that even small additions of titanium contribute to the polymerization of sols and the production of stable gels. Intercalation compounds based on such complex vanadium and titanium oxides are characterized by high intercalation capacity and thermal stability.

\section{ACKNOWLEDGMENTS}

The work was carried out as part of a research project No AP05130830 "Development of technology for demetallization and desulfurization of heavy oil residues to produce coke" of grant financing of Ministry of education and science of Republic of Kazakhstan for 2018-2020.

\section{REFERENCES}

1. J.M. Lee; S. Shin; S. Ahn; J.H. Chun; K.B. Lee; S. Mun; S.G. Jeon; J.G. Na; N.S. Nho; Fuel Process. Tech., 2014, 119, 204-210.

2. R.C. Hansford; Patent of US 3088908, 1963.

3. Patent of US 4435272, 1984.

4. R. Pfeiffer; D. Borey; C. Jahnig; Patent of US 2881130, 1953. 
5. Chem. Eng. News, 1968, 3, 46.

6. L. Bandura; A. Woszuk; D. Kolodynska; W. Franus; Minerals, 2017, 7, 37-52.

7. Y. Ongarbayev; Sh. Oteuli; Y. Tileuberdi; G. Maldybaev; S. Nurzhanova; Petrol. Sci. \& Tech., 2019, 37, 1045-1052.

8. X. Zhao; Y. Liu; C. Xu; Y. Yan; Y. Zhang; Q. Zhang; S. Zhao; K. Chung; M.R. Gray; Q. Shi; Energy \& Fuels, 2013, 27, 2874-2882.

9. T. Liu; J. Lu; Y. Zhou; Q. Wei; C. Xu; Y. Zhang; S. Ding; T. Zhang; X. Tao; L. Ju; Q. Shi; Energy \& Fuels, 2015, 29, 2089-2096.

10.F. Zheng; C.S. Hsu; Y. Zhang; Y. Sun; Y. Wu; H. Lu; X. Sun; Q. Shi; Energy \& Fuels, 2018, 32, 10382-10390. 
